\title{
Harvesting bilateral internal thoracic arteries using a novel subxiphoid approach versus the conventional lateral thoracic approach—results of an experimental study
}

\author{
Chikako Ikeda, MD, Go Watanabe, MD, PhD, Norihiko Ishikawa, MD, PhD, Hiroshi Ohtake, MD, PhD, and \\ Shigeyuki Tomita, MD, PhD
}

\begin{abstract}
Objectives: A new method was developed to harvest bilateral internal thoracic artery grafts using a subxiphoid approach and robotic assistance. The present study compared the potential utility of the subxiphoid method with that of the lateral thoracic approach.
\end{abstract}

\begin{abstract}
Methods: The first part of the study examined the optimal placement of the instrument ports to maximize the robotic arms' range of motion. The second part of the study examined the 2 approaches for harvesting bilateral internal thoracic arteries from pig carcasses. The obtained graft lengths and time needed to conduct each procedure were compared using the Mann-Whitney $U$ test.
\end{abstract}

\begin{abstract}
Results: The preliminary study suggested that optimal positioning of the instrument ports was achieved by placing the right and left instrument ports far apart and linearly arranging all the ports. Using this configuration, the subxiphoid approach yielded a left internal thoracic artery that was $11.7 \pm 1.90 \mathrm{~cm}$ long compared with 9.17 $\pm 0.74 \mathrm{~cm}$ using the conventional approach $(P=.0131)$. The right internal thoracic arteries $(11.8 \pm 1.69 \mathrm{~cm})$ obtained using the subxiphoid approach were significantly longer than those obtained using the conventional approach $(8.88 \pm 0.58 \mathrm{~cm})$. The time needed to harvest the right internal thoracic arteries $(34.7 \pm 8.14$ minutes $)$ was significantly shorter using the subxiphoid approach than using the conventional approach $(52.3 \pm 8.21$ minutes).
\end{abstract}

Conclusions: Because of the maximized lengths of the grafts and the duration of the procedure, the robot-assisted subxiphoid approach could be an effective method for performing minimally invasive myocardial revascularization in patients with multivessel disease. (J Thorac Cardiovasc Surg 2014;148:461-7)

Video clip is available online.

Coronary artery bypass grafting (CABG) has been associated with low morbidity and mortality and has provided reliable long-term results. However, the invasiveness of this procedure and the requirement for cardiopulmonary bypass result in longer hospital stays. ${ }^{1}$ When a pedicled, sequential, or free aortocoronary internal thoracic artery (ITA) is used, the clinical and angiographic outcomes of bilateral ITA (BITA) grafting have been superior to those of single ITA grafting with supplemental vein grafts. ${ }^{2}$ BITA grafting has also been identified as an independent

\footnotetext{
From the Department of General and Cardiothoracic Surgery, Kanazawa University Graduate School of Medicine, Kanazawa, Ishikawa, Japan.

Disclosures: Authors have nothing to disclose with regard to commercial support.

Received for publication June 10, 2013; revisions received Aug 13, 2013; accepted

for publication Sept 13, 2013; available ahead of print Nov 18, 2013.

Address for reprints: Chikako Ikeda, MD, Department of General and Cardiothoracic

Surgery, Kanazawa University Graduate School of Medicine, 13-1 Takara-machi,

Kanazawa, Ishikawa 920-8640, Japan (E-mail: iketti@mac.com).

$0022-5223 / \$ 36.00$

Copyright (c) 2014 by The American Association for Thoracic Surgery

http://dx.doi.org/10.1016/j.jtcvs.2013.09.039
}

predictor of lower rates of angina recurrence, late myocardial infarctions, and lower numbers of composite endpoints for cardiac events. ${ }^{2}$ The minimally invasive direct coronary artery bypass technique combines the advantages of limited surgical access with the benefits of off-pump surgery and leads to faster patient recovery; however, it is restricted to the revascularization of a single vessel in 1 area of the heart.

Endoscopic surgery further limits the dexterity and depth perception of the surgeon. In addition, working through trocars limits the freedom of movement and introduces an inverted instrument response and variability in the excursion of the inserted instrument tip from the body cavity. ${ }^{4}$ These disadvantages require surgeons to acquire new techniques and practices for performing complex surgical maneuvers during endoscopic procedures, such as challenging dissections and suturing. ${ }^{4-6}$ Thus, robotic telemanipulation is a powerful tool, because it further minimizes surgical access, particularly during harvesting of entire lengths of BITAs. ${ }^{7,8}$ Moreover, robotic telemanipulation allows additional optimization of minithoracotomy incisions for coronary anastomoses. ${ }^{1}$ We introduced a robotic telemanipulation system (the da Vinci Surgical System, Intuitive Surgical Inc, Sunnyvale, Calif) in December 2005. The technological advantages of the system include a true 3-dimensional 


$$
\begin{aligned}
& \text { Abbreviations and Acronyms } \\
& \text { BITA }=\text { bilateral internal thoracic artery } \\
& \text { CABG }=\text { coronary artery bypass grafting } \\
& \text { ITA }=\text { internal thoracic artery } \\
& \text { LITA }=\text { left ITA } \\
& \text { RITA }=\text { right ITA }
\end{aligned}
$$

endoscope that provides a high-resolution binocular view of the surgical field, an instrument system capable of $7^{\circ}$ of freedom and $2^{\circ}$ of axial rotation to mimic human wrist movements and tremor filtration, and a motion-scaling system to enhance surgical dexterity.

In the present study, we performed a new linear BITA harvesting approach using a subxiphoid approach and robotic manipulation and compared this approach with the conventional lateral thoracic approach in an animal model.

\section{METHODS}

\section{Phase I: Simulator Model}

The baseline settings were determined by performing a simulated experiment to evaluate the changes in the exfoliation range, depending on the position of the endoscopy port, for specific operational procedures using the standard da Vinci Surgical System (Intuitive Surgical, Inc) and a $30^{\circ}$ angle-up camera. The instrument ports were symmetrically placed on the right and left side of the camera port. A movable axis for each port was placed horizontally, $20 \mathrm{~cm}$ above the table, and the angle of the instrument arm was adjusted to approximately $45^{\circ}$. The distance between the right and left instrument ports was defined as "a"; and the distance between the movable axis of the camera arm (base point) and the marked point on the movable axis of the instrument port was defined as "b" (Figure 1).

To position the ports, group 1 (distance a, $10 \mathrm{~cm}$; distance $\mathrm{b}, 1 \mathrm{~cm}$ ) and group 2 (distance a, $6 \mathrm{~cm}$; distance $\mathrm{b}, 1 \mathrm{~cm}$ ) formed an isosceles triangle, and group 3 (distance a, $10 \mathrm{~cm}$; distance $\mathrm{b}, 0 \mathrm{~cm}$ ) and group 4 (distance a, $6 \mathrm{~cm}$; distance b, $0 \mathrm{~cm}$; Figure 1), a straight line. An inverted triangle pattern was excluded, because it interfered with the instrument arms. Video footage was recorded from the top of the instrument arms during surgery to calculate the range of motion for each pattern (Figure 2), using Hakarundesu PRO software (Kazuyoshi Natsume, Shizuoka, Japan). The range of motion for each pattern, in the horizontal and vertical planes, was calculated to obtain the area described by the range of motion of the instrument arms, and the resultant areas among the different patterns were compared. This procedure optimized the placement of the instrument ports.

\section{Phase II: Animal Experiments}

The subjects for the second phase of the study included 12 pig carcasses obtained from our animal facility, with a median weight of $30.8 \pm 4.9 \mathrm{~kg}$ (range, 28-38). All experimental procedures were performed in accordance with the "Principles of Laboratory Animal Care," formulated by the National Society for Medical Research, and the "Guide for the Care and Use of Laboratory Animals," prepared by the Institute of Laboratory Animal Resources of the US National Research Council.

\section{Linear Harvesting Technique Using Subxiphoid Approach}

A surgical cart was positioned at the head of the table, with a pig carcass placed in the supine position, in which a $3-\mathrm{cm}$ incision was made under the xiphoid process along the median line. The subxiphoid incision served as the camera port for the robotic system and enabled the insertion of a $30^{\circ}$ angle-up camera. A lifting retractor was inserted behind the sternum, through the subxiphoid incision, and lifted horizontally. The instrument ports were symmetrically placed on the right and left side of the subxiphoid incision, under direct vision through the camera (Figure 3). We determined the optimal port positions from the results of the phase I study and used the port position of group 3 for the phase II experiment (see the "Results" section). The BITAs were dissected using a $30^{\circ}$ angle-up camera. The skeletonized harvesting technique used was similar to that used for open or endoscopic surgery and involved blunt and sharp dissection with an EndoWrist cautery hook (Intuitive Surgical) on 1 robotic arm and EndoWrist deBakey forceps (Intuitive Surgical) on the other. The ITA was harvested from its adhesion site on the first rib to the first bifurcation on the sixth rib, and the branches were coagulated or clipped endoscopically (Figure 4, Video 1).

\section{Conventional Lateral Thoracic Approach}

Given our understanding that the lateral approach method was already widely established and the ideal port position had already been determined, we did not conduct basic experiments to determine the port position in the present study and performed our experiment in accordance with the standard method. ${ }^{9}$ Three incisions were made in the second, fourth, and sixth intercostal spaces slightly medial to the anterior axillary line. A port was inserted through the middle incision, and a $30^{\circ}$ angle-up camera was inserted. The left and the right instrument ports were inserted under direct vision through the camera. A surgical cart with 3 mechanical arms was attached to the camera and the instrument arm ports.

After finishing both procedures, the BITAs were proximally transected (Figure 4), and the conduit lengths of the free left ITA (LITA) and right ITA (RITA) and the total harvesting times were compared.

\section{Statistical Analysis}

The subxiphoid approach and the conventional lateral thoracic procedure were performed on 6 pig carcasses. All data are presented as mean \pm standard deviation. Comparative analyses were performed using the Mann-Whitney $U$ test and Statistical Package for Social Sciences, version 11.0, software (SPSS, Chicago, Ill).

\section{RESULTS}

\section{Phase I: Simulator Model}

The vertical range of motion for each group was as follows: group 1, $183.3 \mathrm{~cm}^{2}$; group 2, $181.9 \mathrm{~cm}^{2}$; group 3, $182.9 \mathrm{~cm}^{2}$; and group 4, $178.8 \mathrm{~cm}^{2}$. The horizontal range of motion for each group was as follows: group 1, $287.3 \mathrm{~cm}^{2}$; group 2, $276.3 \mathrm{~cm}^{2}$; group 3, $417.4 \mathrm{~cm}^{2}$; and group 4, $405.2 \mathrm{~cm}^{2}$ (Figure 5). In the vertical direction, little difference was found in the range of motion among the 4 patterns. In the horizontal direction, however, the range of motion was greater for groups 3 and 4 , with the 3 ports positioned in a straight line affording greater range of motion (Figure 5). These results suggest that the theoretically optimal position was obtained when the right and left instrument ports were placed as far apart as possible, and all the ports were set in a horizontal straight line. These principles were applied to the basic operational procedure in the animal experiments. We determined the ideal port positions from the results of phase I and used the port position for group 3 for the phase II experiments.

\section{Phase II: Animal Experiments}

All BIMAs were successfully harvested in a skeletonized fashion. After harvesting the BIMAs, they were 

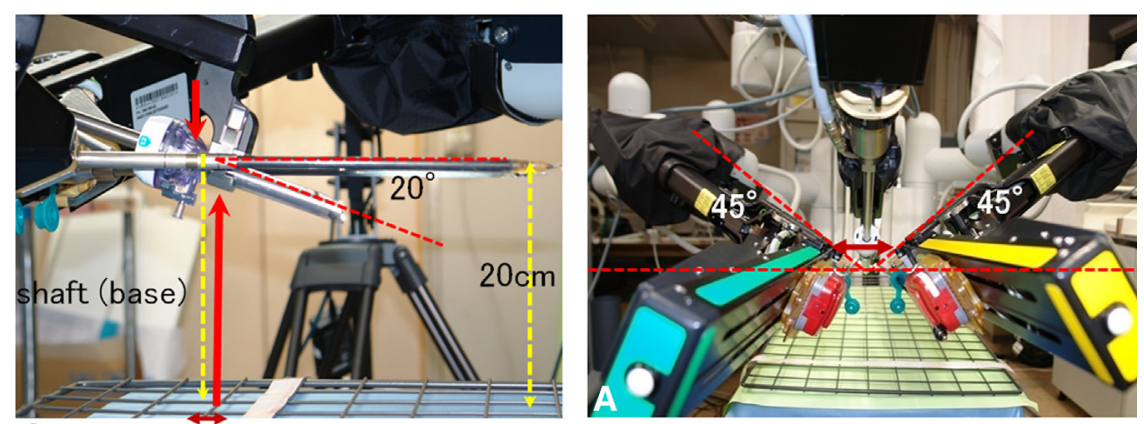

A
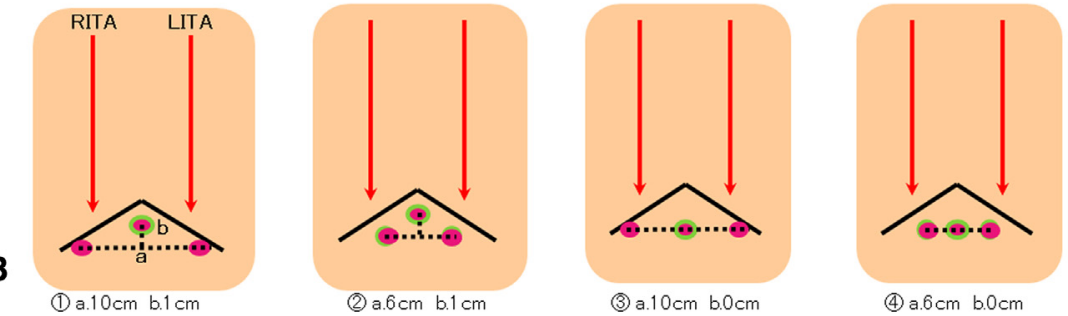

FIGURE 1. Phase I: dry-laboratory model, baseline setting. A $30^{\circ}$ angle-up camera was used. A, Distance between instrument ports (10 $\mathrm{cm}$ or 6 $\mathrm{cm})$. B, Vertical distance between the camera port and the instrument ports $(1 \mathrm{~cm}$ or $0 \mathrm{~cm})$. RITA, Right internal thoracic artery; LITA, left internal thoracic artery.

proximally transected, and the lengths of the free grafts were compared.

The average length of the LITAs (free grafts) was $11.7 \pm 1.90 \mathrm{~cm}$ using the subxiphoid approach compared with $9.17 \pm 0.74 \mathrm{~cm}$ using the conventional lateral thoracic approach $(P=.0131)$. The average length of the RITAs was $11.8 \pm 1.69 \mathrm{~cm}$ using the subxiphoid approach and $8.88 \pm 0.58 \mathrm{~cm}$ using the lateral thoracic approach $(P=.00824$; Table 1$)$. The length of both conduits was significantly longer with the subxiphoid approach than with the lateral thoracic approach.

The total mean time for the robotic harvesting of the LITAs using the subxiphoid approach was $39.7 \pm 13.2 \mathrm{mi}-$ nutes compared with $43.3 \pm 13.7$ minutes using the lateral thoracic approach $(P=.521)$. RITA harvesting using the subxiphoid approach averaged $34.7 \pm 8.14$ minutes compared with $52.3 \pm 8.21$ minutes using the lateral thoracic approach $(P=.0130$; Table 1$)$. The mean harvesting time for the

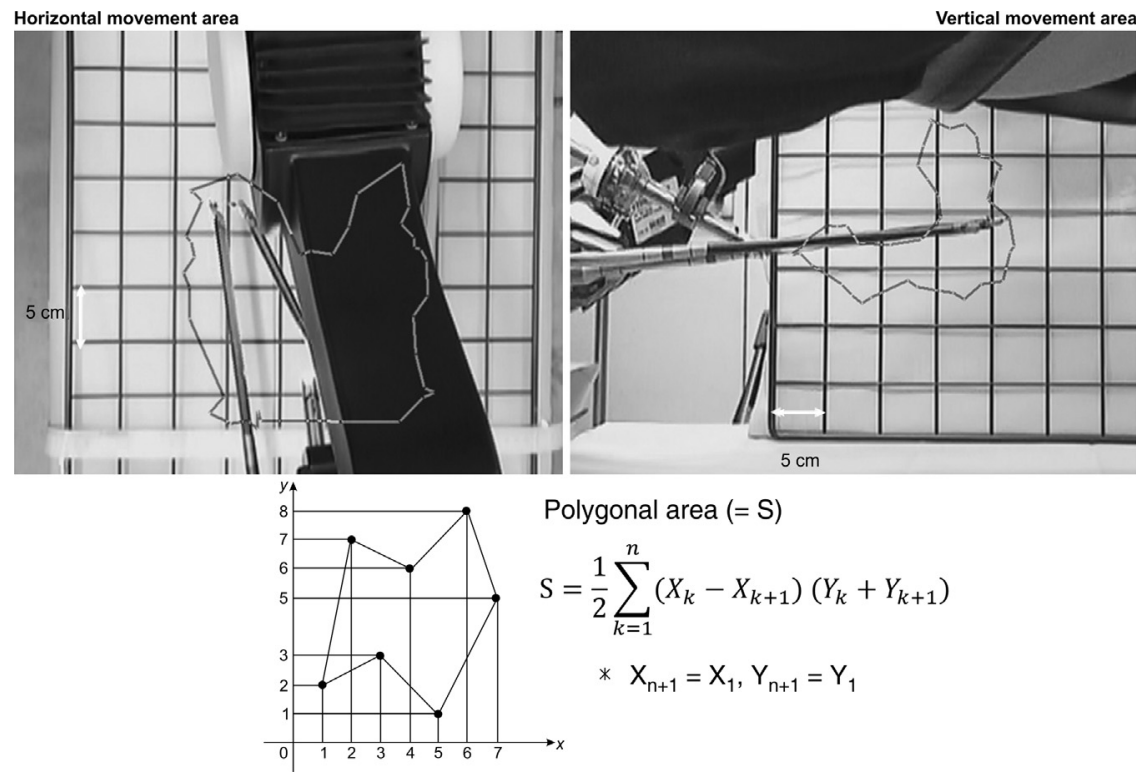

FIGURE 2. Phase I: dry-laboratory model showing analysis of the horizontal and vertical movement area (polygonal area) of the arm. 


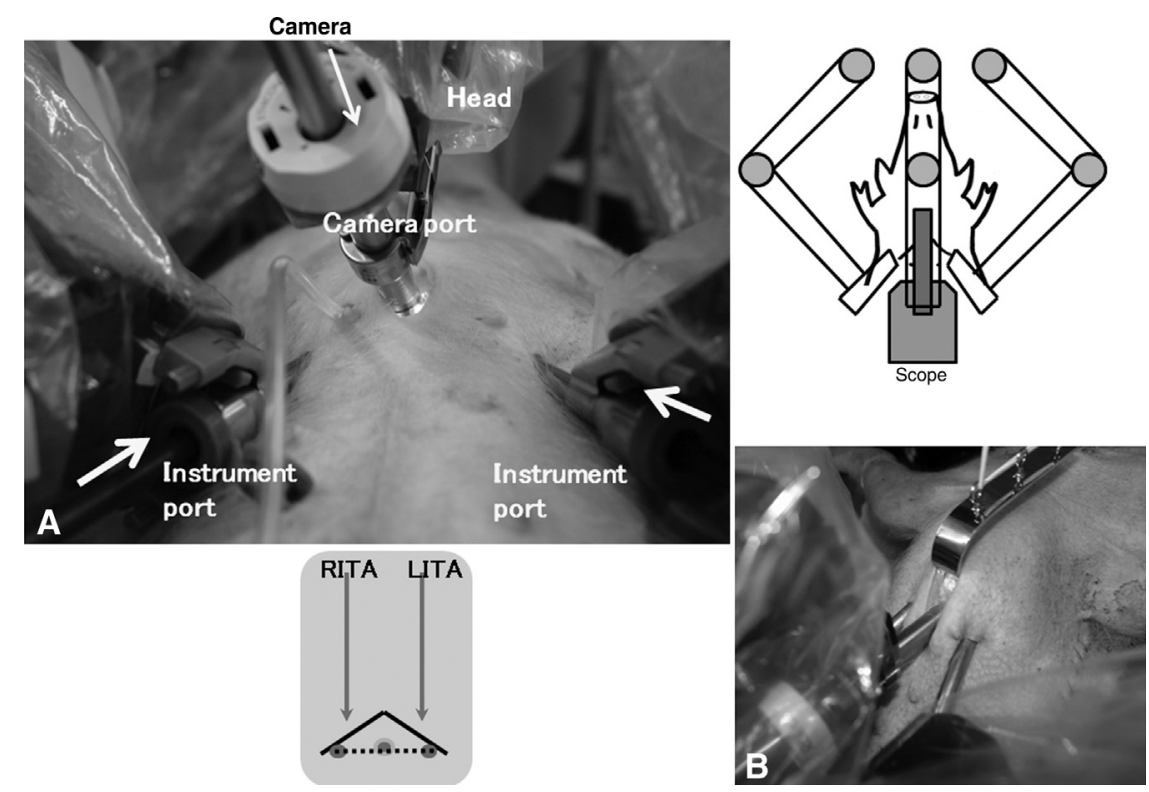

FIGURE 3. Positioning of the robotic system, camera, and instrument ports for the subxiphoid, linear harvesting technique. A, The surgical cart was placed at the head of the table. The instrument ports were placed symmetrically to the right and left of the subxiphoid incision, under direct vision through the camera. B, The chest wall was lifted, and the working space was created. RITA, Right internal thoracic artery; LITA, left internal thoracic artery.

RITAs using the subxiphoid approach was significantly shorter than that with the lateral thoracic approach.

\section{DISCUSSION}

Harvesting the BITAs with robotic assistance using the subxiphoid approach appears to be an effective technique. Although cardiac surgery has lagged far behind other specialties in the development of robot-assisted minimally invasive surgery, significant advances have been made, and encouraging reports have emerged. ${ }^{10-13}$ The superiority of ITA as a conduit has been well established for long-term patency and event-free survival. Robotic assistance has allowed BITA grafting to be performed through a minimally invasive access method. In our animal model results, the length of both conduits was significantly longer using the subxiphoid approach than that using the lateral thoracic approach. In addition, the average harvesting time for RITAs using the subxiphoid approach was significantly shorter than that using the lateral thoracic approach. Thus, robot-assisted BITA harvesting using the
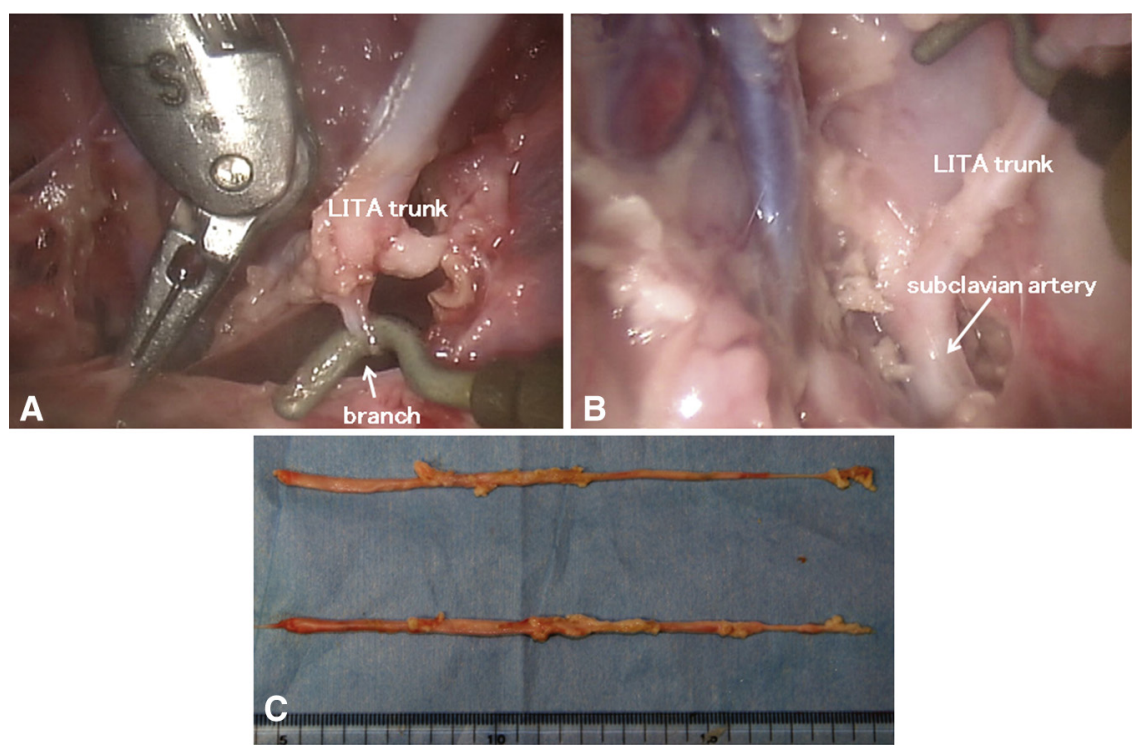

FIGURE 4. Operator's view on the console during the subxiphoid approach. A, The left internal thoracic artery (LITA) trunk and branches. B, Branching of the subclavian artery from the LITA. C, Free LITA grafts. 


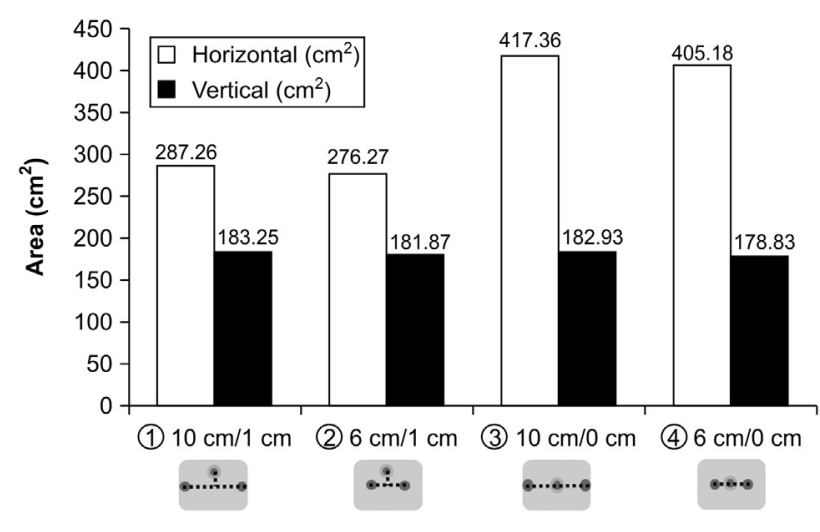

FIGURE 5. Phase I: dry-laboratory model. The range of motion in the vertical direction was $183.3 \mathrm{~cm}^{2}$ for group $1,181.9 \mathrm{~cm}^{2}$ for group $2,182.9 \mathrm{~cm}^{2}$ for group 3 , and $178.8 \mathrm{~cm}^{2}$ for group 4 . The range of motion in the horizontal direction was $287.3 \mathrm{~cm}^{2}$ for group $1,276.3 \mathrm{~cm}^{2}$ for group $2,417.4 \mathrm{~cm}^{2}$ for group 3 , and $405.2 \mathrm{~cm}^{2}$ for group 4 .

subxiphoid approach appears to be safe and provided more grafting material than the thoracic approach.

Endoscopic beating-heart surgery was the initial field of interest for robot-assisted minimally invasive surgery, because the technical challenge of this procedure surpassed the traditional reach of endoscopic techniques. ${ }^{5,6,14}$ However, the 3-dimensional visualization, magnification, and technical dexterity afforded by these robotic systems has also allowed precise harvesting of BITAs in a totally skeletonized fashion. In 1999, Watanabe and colleagues ${ }^{4}$ reported the first case of endoscopic CABG on a beating heart. Since then, several reports have been published concerning the utility of robotic ITA harvesting procedures, including robotic BITA harvesting and robotic coronary artery anastomoses. ${ }^{15}$ Furthermore, a case report has been published of robotic BITA harvesting using the subxiphoid approach. ${ }^{16}$ With the advent of robotic assistance, the time required for BITA harvesting has been significantly reduced. ${ }^{17}$

When the rib cage is elevated during the subxiphoid approach, the lower ribs project directly forward, moving

TABLE 1. Phase II: experimental results from harvesting of internal thoracic arteries

\begin{tabular}{lccc}
\hline \multicolumn{1}{c}{ Variable } & $\begin{array}{c}\text { Subxiphoid } \\
\text { approach }\end{array}$ & $\begin{array}{c}\text { Lateral thoracic } \\
\text { approach }\end{array}$ & $\begin{array}{c}\boldsymbol{P} \\
\text { value }\end{array}$ \\
\hline $\begin{array}{l}\text { Pigs (n) } \\
\text { Length of harvested }\end{array}$ & 6 & 6 & \\
$\quad$ LITA (cm) & $11.7 \pm 1.90$ & $9.17 \pm 0.74$ & .013 \\
$\begin{array}{l}\text { Length of harvested } \\
\quad \text { RITA (free conduit length) }\end{array}$ & $11.8 \pm 1.69$ & $8.88 \pm 0.58$ & .0082 \\
$\begin{array}{l}\text { Time for harvesting } \\
\quad \text { LITA (min) }\end{array}$ & $39.7 \pm 13.2$ & $43.3 \pm 13.7$ & NS \\
$\begin{array}{l}\text { Time for harvesting } \\
\quad \text { RITA (min) }\end{array}$ & $34.7 \pm 8.14$ & $52.3 \pm 8.21$ & .013 \\
\hline $\begin{array}{l}\text { Statistical significance set at } P<.05 . \text { LITA, Left internal thoracic artery; RITA, right } \\
\text { internal thoracic artery. }\end{array}$ & & &
\end{tabular}

the sternum away from the spine and increasing the anteroposterior diameter of the chest by $20 \%{ }^{18}$ A major advantage of the linear harvesting of BITAs, using a subxiphoid approach with robotic assistance, is the provision of sufficient working space owing to the sternal elevation. In addition, superior hemodynamics have been associated with the technique compared with the lateral thoracic approach, because the former does not require an increase in the intrathoracic pressure using gases such as carbon dioxide when harvesting the artery. Furthermore, because single-lung ventilation is unnecessary during BITA harvesting, this procedure is effective for cases involving respiratory complications. Thus, the possibilities of performing conscious $\mathrm{CABG}$ are broadened.

In the present study, we have demonstrated that, using a linear approach, the harvesting of a longer length of the artery is possible, with the time required for detachment shorter. This might have resulted from the simplified and more efficient management of the arterial branches afforded by improving the surgeon's field of vision during artery harvesting (Video 1). Unlike the conventional lateral thoracic approach, in which the ITA is seen from the long axis, the proposed subxiphoid approach facilitates easier identification of the branch arteries, because they are viewed along the short axis. In the subxiphoid approach, the LITA and RITA can be seen from the same distance (Video 1); however, visualization of the RITA will be better because the lateral approach is only conducted through the left side. Therefore, the conduit length - particularly for the RITA - can be longer using the subxiphoid approach than using the lateral thoracic approach. From the operator's view on the console (Video 1), the BITAs were observed to be parallel and linear; imparting the appearance of parallel strips of fluorescence on a long, straight tunnel. ${ }^{16}$ In the lateral approach, because the ITA is observed laterally, branching on the opposite side is difficult to confirm. However, in the subxiphoid approach, the branches extend to the right and left sides and can therefore be relatively easily identified. This view enables the operator to locate small branches more easily than when using the lateral thoracic approach, enabling them to be quickly cauterized or clipped. In addition, branch treatment is safe and secure owing to the improved access to the proximal portion and branches of the conduit.

Long graft harvesting, using a robotic thoracic approach, has been reported in a clinical case. ${ }^{9}$ In that case instance, the harvesting also started at the first rib and continued to the bifurcation of the ITA and subclavian artery. However, questions remain regarding whether any significant difference existed in the length of the harvested conduit with the results obtained using the current subxiphoid approach.

As previously reported by Subramanian and Patel, ${ }^{17}$ the gastroepiploic artery can also be harvested and 
anastomosed in the same operative field using the subxiphoid approach. The number of branches anastomosed during robot-assisted CABG has been reported to average 2.2 to 2.6 branches. ${ }^{1,18}$ Using linear harvesting and the subxiphoid approach, longer lengths of the RITA could possibly be detached, raising the possibility of CABG and multivessel CABG.

The present study had limitations that warrant mention. First, the use of carcasses instead of a live porcine model. The harvesting time comparisons cannot be realistic without the compounding problems associated with a live experiment. The carcasses had no bleeding, no lungs present, and no heart beating. Comparing the harvesting times might not be realistic, given the lack of bleeding, lungs, and beating heart in the present study. In clinical practice, ${ }^{16}$ harvesting of the RITA using the lateral approach has been conducted from the left thoracic cavity beyond the mediastinum, rendering central side separation to the bifurcation of the subclavian artery technically difficult; thus, the harvested RITAs tend to be shorter. We, therefore, attempted to identify a better method for harvesting longer RITAs. We believe that, rather than comparing the harvesting times, our results emphasize that longer RITAs are likely to be harvested using the subxiphoid approach, because no differences are present between the right and left visual fields.

A subxiphoid approach involving a lifting sternal method was introduced by Ishikawa and colleagues ${ }^{19}$ and Bakker and colleagues. ${ }^{20}$ In our study, the mediastinum was lifted in the same manner as that reported by Takata and colleagues, ${ }^{16}$ Ishikawa and colleagues,${ }^{19}$ and Bakker and colleagues. ${ }^{20}$ This method provides an excellent view and increases the limited working space for thoracoscopic maneuvers. ${ }^{20,21}$

A clinical surgery case report described an instance in which the subxiphoid approach was actually performed in a human in a related facility. ${ }^{16}$ One of us (N.I.) participated in that surgery. The excellent view available with the subxiphoid approach facilitates safe surgery, even with bleeding, lungs present, and a beating heart. We, therefore, believe that the use of pig carcasses in the present study did not significantly affect the results.

The second limitation of this experiment revolved around the use of the robotic system used. Although we used the standard model of the standard da Vinci, a more advanced da Vinci S system is available that is more compact and has more flexible arms. The use of this advanced system might increase the ease of use of this method.

The third limitation was requiring additional ports for anastomoses. However, the incision made for harvesting the ITA can be used as a port for the stabilizer. When considering the merits of ITA harvesting, we have regarded the incision as useful.
Finally, new surgical approaches usually contain a steep learning curve, ${ }^{10}$ which could also be the case with the robot-assisted subxiphoid approach.

In conclusion, the robot-assisted subxiphoid approach appears to be an effective method of performing minimally invasive myocardial revascularization in patients with multivessel disease. This approach could be an evolutionary step toward enabling surgeons to perform less invasive multivessel CABG.

\section{References}

1. Subramanian VA, Patel NU, Patel NC, Loulmet DF. Robotic assisted multivessel minimally invasive direct coronary artery bypass with port-access stabilization and cardiac positioning: paving the way for outpatient coronary surgery? Ann Thorac Surg. 2005;79:1590-6.

2. Rizzoli G, Schiavon L, Bellini P. Does the use of bilateral internal mammary artery (IMA) grafts provide incremental benefit relative to the use of a single IMA graft? A meta-analysis approach. Eur J Cardiothorac Surg. 2002; 22:781-6.

3. Subramanian VA, Patel NU. Current status of MIDCAB procedure. Curr Opin Cardiol. 2001; 16:268-70.

4. Watanabe G, Takahashi M, Misaki T, Kotoh K, Doi Y. Beating-heart endoscopic coronary artery surgery. Lancet. 1999;354:2131-2.

5. Waseda R, Ishikawa N, Oda M, Matsumoto I, Ohta Y, Inaki N, et al. Robotassisted endoscopic airway reconstruction in rabbits, with the aim to perform robot-assisted thoracoscopic bronchoplasty in human subjects. J Thorac Cardiovasc Surg. 2007;134:989-95.

6. Mohr FW, Falk V, Diegeler A, Autschback R. Computer-enhanced coronary artery bypass surgery. J Thorac Cardiovasc Surg. 1999;117:1212-4.

7. Dogan S, Aybek T, Anderben E, Byhahn C, Mierdl S, Westphal K, et al. Totally endoscopic coronary artery bypass grafting on cardiopulmonary bypass with robotically enhanced telemanipulation: report of forty five cases. J Thorac Cardiovasc Surg. 2002;123:1125-31.

8. Boehm DH, Reichenspurner H, Gulbins H, Detter C, Meiser B, Brenner P, et al. Early experience with robotic technology for coronary artery surgery. Ann Thorac Surg. 1999;68:1542-6.

9. Ishikawa N, Watanabe G, Iino K, Tomita S, Yamaguchi S, Higashidani K, et al. Robotic internal thoracic artery harvesting. Surg Today. 2007;37: 944-6.

10. Watanabe G, Yamaguchi S, Tomita S, Ohtake H. Awake subxiphoid minimally invasive direct coronary artery bypass grafting yielded minimum invasive cardiac surgery for high risk patients. Interact Cardiovasc Thorac Surg. 2008;7:910-2

11. Gao C, Yang M, Wanf G, Wang J, Xiao C, Wu Y, et al. Totally endoscopic robotic ventricular septal defect repair in the adult. J Thorac Cardiovasc Surg. 2012;144: 1404-7.

12. Gao C, Yang M, Wu Y, Wang G, Xiao C, Zhao Y, et al. Early and midterm results of totally endoscopic coronary artery bypass grafting on the beating heart. J Thorac Cardiovasc Surg. 2011;142:843-9.

13. Bonatti J, Lehr EJ, Schachner T, Wiedemann D, et al. Robotic total endoscopic double-vessel coronary artery bypass grafting — state of procedure development. J Thorac Cardiovasc Surg. 2012;144:1061-6.

14. Mohr FW, Falk V, Diegeler A, Walther T, Gummert JF, Bucerius J, et al. Computer-enhanced "robotic" cardiac surgery: experience in 148 patients. J Thorac Cardiovasc Surg. 2001;121:842-53.

15. Nishida S, Yasuda T, Watanabe G, Kikuchi Y, Shintani Y, Ito S, et al. Robotically assisted multivessel minimally invasive direct coronary artery bypass grafting with the use of bilateral internal thoracic arteries. Circ J. 2007;71: 1496-8.

16. Takata M, Watanabe G, Ushijima T, Ishikawa N. A novel internal thoracic artery harvesting technique via subxiphoid approach-for the least invasive coronary artery bypass grafting. Interact Cardiovasc Thorac Surg. 2009;9: 891-2.

17. Subramanian VA, Patel NU. Transabdominal minimally invasive direct coronary artery bypass grafting (MIDCAB). Eur J Cardiothorac Surg. 2000; $17: 485-7$. 
18. Srivastava S, Gadasalli S, Agusala M, Kolluru R, Naidu J, Shroff M, et al. Use of bilateral internal thoracic arteries in $\mathrm{CABG}$ thorough lateral thoracotomy with robotic assistance in 150 patients. Ann Thorac Surg. 2006;81:800-6.

19. Ishikawa N, Sun YS, Nifong LW, Oda M, Watanabe G, Chitwood WR Jr. Thoracoscopic robot-assisted extended thymectomy in human cadaver. Surg Endosc. 2009;23:459-61.
20. Bakker PF, Budde RP, Gründeman PF. Endoscopic robot-assisted extended thymectomy by subxiphoid approach with sternal lifting: feasibility in the pig Surg Endosc. 2004;6:986-9.

21. Robin J, Bompard D, Tronc F, Beaune J, Wahid F, Champsaur G. Bilateral internal thoracic artery harvesting under robotic video-assistance. Surg Endosc. 2001; 15:755-6.

Access to The Journal of Thoracic and Cardiovascular Surgery Online is reserved for print subscribers!

Full-text access to The Journal of Thoracic and Cardiovascular Surgery Online is available for all print subscribers. To activate your individual online subscription, please visit The Journal of Thoracic and Cardiovascular Surgery Online, point your browser to http://www.mosby.com/jtcvs, follow the prompts to activate your online access, and follow the instructions. To activate your account, you will need your subscriber account number, which you can find on your mailing label (note: the number of digits in your subscriber account number varies from 6 to 10 ). See the example below in which the subscriber account number has been circled:

\section{Sample mailing label}

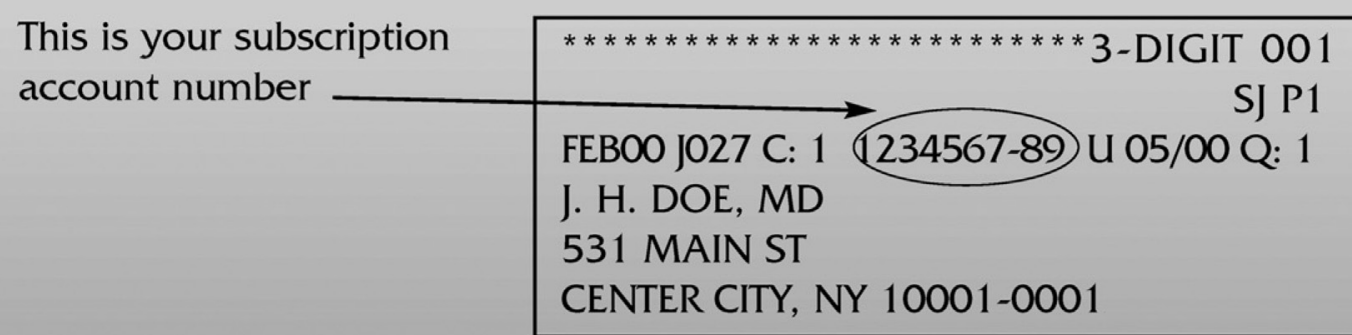

Personal subscriptions to The Journal of Thoracic and Cardiovascular Surgery Online are for individual use only and may not be transferred. Use of The Journal of Thoracic and Cardiovascular Surgery Online is subject to agreement to the terms and conditions as indicated online. 